\title{
Metodologías interdisciplinares como herramienta para motivar a alumnado de altas capacidades
}

\author{
Verónica Navarro Navarro *
}

Resumen. A través de esta investigación se abordan factores que pueden ser importantes para el aprendizaje del alumnado en general y de altas capacidades en particular. Para ello se han implementando actividades interdisciplinares que fomenten la motivación, no sólo mediante la conexión entre las áreas, sino aplicando el juego, valorando la expresión de sus emociones y su creatividad y exponiendo su trabajo fuera del centro educativo. Dicha investigación parte del taller "Del barroco al arte contemporáneo", que se enmarca dentro del programa "Talleres de Enriquecimiento Extracurricular para alumnos de altas capacidades" en la Región de Murcia, España, para 11 alumnos/as de $6^{\circ}$ curso de Educación Primaria.

Palabras clave: interdisciplinariedad; emociones; juego; creatividad; neurodidáctica; neuroeducación; neurociencias.

METODOLOGIAS INTERDISCIPLINARES COMO FERRAMENTA PARA MOTIVAR OS ALUNOS COM ALTAS HABILIDADES/SUPERDOTAÇÃO

Resumo. Nesta pesquisa são abordados fatores que podem ser importantes para a aprendizagem dos alunos em geral e, particularmente, dos alunos com altas habilidades. Para tanto, foram implementadas atividades interdisciplinares que fomentem a motivação, não apenas mediante a conexão entre as áreas, mas pela aplicação de jogos e brincadeiras, valorizando a expressão de suas emoções e sua criatividade e expondo o seu trabalho fora do centro educacional. Esta pesquisa baseia-se no projeto "Do Barroco à Arte Contemporânea", que faz parte do programa "Oficinas de Enriquecimento Extracurricular para alunos com altas habilidades" na Região de Múrcia, na Espanha, para 11 alunos do $6^{\circ}$ ano da Educação Primária.

Keywords: Interdisciplinary; emotions; game; creativity.

INTERDISCIPLINARY METHODOLOGIES AS A TOLL FOR MOTIVATING HIGH ACHIEVING STUDENTS

Abstract. This research deals with important aspects in the general learning of students and in high achieving pupils in particular. Interdisciplinary activities have been planned in the aim of triggering motivation not only through connecting different areas of study, but also including games, valuing the expression of emotions and creativity. Students will also show their works outside the school. This research stems from the workshop "From Baroque to Contemporary Art", which is part of the project program "Workshops of Extracurricular enrichment for high achieving Pupils" in the region of Murcia, Spain for eleven students in the 6th year of Primary Education.

Keywords: Interdisciplinary; emotions; game; creativity

\footnotetext{
* Laboratorio artístico y educativo Puntodepapel, España.
} 


\section{INTRODUCCIÓN Y ESTADO DE LA CUESTIÓN}

En nuestro sistema educativo encontramos diversos problemas con los que trabajar y solucionar, entre los más destacables y repetidos es la falta de motivación. Es un tema que preocupa a docentes y familias, pues se observa, en muchas ocasiones, a un alumnado que rechaza la escuela por falta de motivación. Por ello, se hace necesario conocer el problema para poder abordar y mejorar la metodología implementada en el aula, buscando soluciones que estimulen al alumnado y despierten el deseo e interés por aprender contenidos tanto dentro como fuera del aula. $Y$ es que no nos vale afirmar que el alumnado no se siente motivado y no tiene interés por aprender, ya que si analizamos un poco, estos tienen intereses hacia contenidos o actividades fuera del aula ya que el ser humano es por naturaleza curioso y se encuentra deseoso de aprender. Entonces ¿qué origina la falta de motivación?

La motivación sigue siendo, a día de hoy, una preocupación inherente al sistema educativo. Estamos acostumbrados a escuchar hablar sobre dicho problema a personas integrantes del sistema educativo, donde el docente se siente incapacitado o fracasado en su trabajo y el alumno se siente alejado de dicho sistema. Por ello es importante buscar estrategias, nuevas metodologías o modos de mostrar los contenidos que despierten la curiosidad y motivación del alumnado que incidirá favorablemente en la frustración del docente.

Son varios los elementos que pueden intervenir en despertar la motivación, cabe destacar:

- Empleo de una metodología globalizada que aunque sigue siendo un reto para muchos docentes, puede fomentar la atracción del alumnado al permitir que cada alumno/a acceda al conocimiento desde el área que le resulte más favorable, a la vez que desarrolle habilidades o capacidades.

- Atender a las emociones del alumnado, por ser la puerta de acceso al interés. No es fácil motivar sin despertar o conectar con éstas, ya que ayudan a la memoria.

- El juego como herramienta motivadora, capaz de favorecer el aprendizaje y la participación, al minimizar e incluso eliminar el fallo o el error como signo de fracaso.

- Desarrollo de la creatividad, donde se apueste por un pensamiento crítico y se genere la necesidad de buscar nuevas respuestas a las ya establecidas. 
La investigación propone analizar aspectos importantes que intervienen en el aprendizaje significativo del alumnado, atendiendo a estudios recientes sobre neuroeducación que nos advierten de la necesidad de cambiar el modo de enseñar. Desde dicha posición, estudiaremos un proyecto concreto, "Del barroco al arte contemporáneo", el cual se enmarca dentro del programa "Talleres de Enriquecimiento Extracurricular para alumnos de altas capacidades" en la Región de Murcia, España, basado en una metodología interdisciplinar que aúna diferentes áreas del currículo (arte, literatura y matemáticas, entre otras), a la vez que valora otros factores que dialogan con éstas, como son las emociones, la creatividad y el juego y participan activamente en el proceso. Una investigación llevada a cabo en talleres extraescolares que puede ser transferible al aula, donde se obtienen resultados que nos permiten recabar información sobre aspectos positivos y negativos de dicha investigación.

\section{FUNDAMENTOS Y ANTECEDENTES.}

\subsection{La neuroeducación, estudios sobre el aprendizaje del alumnado}

Para hablar de neurodidáctica debemos, en primer lugar, ser conscientes de que es una nueva perspectiva de la enseñanza, basada en la neurociencia, que pretende conocer cómo funciona el cerebro para desde aquí, averiguar aspectos que sean útiles para el aprendizaje. Comprender cómo funciona y responde nuestro cerebro ante determinados estímulos, acciones, metodologías, espacios... Un estudio cuyo propósito es encontrar herramientas: que favorezcan el aprendizaje en general y de forma individual; que faciliten la localización de problemas neurológicos y psicológicos que afectan al aprendizaje; que formen ciudadanos con un pensamiento crítico donde encuentren el equilibrio entre la emoción y la cognición; y herramientas que faciliten no solo el aprendizaje, sino también la enseñanza (Francisco Mora, 2017).

Entre los aspectos que pone en relieve, por su implicación en el aprendizaje del alumnado son: la emoción, la atención, el juego, la curiosidad, la motivación, la creatividad, el trabajo colectivo, entre otros.

El juego es uno de los focos de atención, pues éste es con el que cualquier mamífero comienza a aprender. El juego implica curiosidad, riesgos, placer, emoción, recompensa... Y es que este placer es el mecanismo que empuja al niño al deseo de conocer, de investigar, Ilevándolo a un aprendizaje desde la motivación y el placer. Éste es un recurso que combina curiosidad y placer por lo que es un instrumento poderoso para utilizarlo como medio del aprendizaje. 
El juego se ha relacionado y se relaciona con una actividad de entretenimiento que se aleja del aprendizaje y el conocimiento. Muchos autores han reflexionado sobre los beneficios de dicha actividad, pero aún nos resistimos a darle el valor que merece. Por ello creo importante volver a hablar del juego, para recordar las ventajas de su implementación en el aula y desde aquí seamos capaces de integrarlo.

Para hablar de juego y la importancia del mismo en el desarrollo del niño, debemos citar a Vygotski (1989), quien expone y valora la capacidad creadora de los niños manteniendo una postura firme en cuanto a la necesidad de atenderla y fomentarla para su desarrollo general y su preparación a la madurez. En los juegos de la infancia es donde se observan los primeros signos de creatividad, al combinar y reelaborar vivencias y experiencias anteriores. Porque el proceso creativo lo describe como aquel donde la imaginación transforma los elementos procedentes de la realidad, devolviéndolos de nuevo al mundo.

Lo que nos lleva a hablar de buenas experiencias, experiencias enriquecedoras que conectan con nuestras emociones y que serán a través de la fantasía y la imaginación las que favorezcan el proceso creativo. Por tanto, existe una relación directa entre juego y creatividad que no debemos olvidar.

Como afirma Huizinga (2010) en su libro Homo ludens, el juego está presente no sólo en la especie humana, sino también en los animales, por lo que es intrínseco a ambos. Y es que cuando nos referimos al juego, debemos escapar de la idea de una actividad de mero entretenimiento, ya que éste desarrolla nuestras destrezas motoras y físicas y además nos prepara para la madurez. A diferencia con el resto de animales, a través del juego el ser humano aprende habilidades sociales relacionadas con su desarrollo afectivo y desarrollo cognitivo, ambos conectados con la creatividad.

A lo que debemos añadir su capacidad de provocar placer, llegando incluso a absorber completamente al jugador. Se juega dentro de un espacio y un tiempo, teniendo sentido en dicho marco espacio temporal. Cuando acaba este tiempo el juego queda como recuerdo, como creación, pudiendo repetirlo en cualquier momento.

Esto último tiene un gran valor porque, si lo trasladamos al aula, es una herramienta poderosa que puede atraer al alumnado produciéndose el conocimiento desde el placer y alejado del miedo. 
La emoción es un proceso inconsciente empleado por el ser humano para asentar los procesos de memoria y aprendizaje. Y es que no hay aprendizaje sin emoción, pues la emoción es la que despierta la curiosidad y la atención con el objetivo de descubrir algo. Esta emoción, al igual que el juego, viene impulsada por el placer, un placer provocado por la recompensa que recibe el cerebro.

Y es que la motivación e incluso el razonamiento están ligados a las emociones, empujándonos a hacer aquello que nos interesa, incluso disfrutar del aprendizaje, y dejar aparcado aquello que no despierta nuestro interés. Trasladando esto al sistema educativo y a nuestro modo de aprender, debemos generar ambientes adecuados, donde: generar niveles de estrés que ni aburran por su simplicidad, ni paralicen al alumnado por su dificultad; se utilice la risa como herramienta para obtener beneficios físicos, cognitivos y emocionales, entre otros, minimizando la idea de fracaso y asumiendo el error como parte del aprendizaje.

Trabajar la educación emocional tanto emociones que consideramos positivas, como emociones consideradas negativas, ayudando a la buena gestión de ambas. Teniendo en cuenta que las competencias emocionales son complementarias a las competencias cognitivas, no sustitutivas.

$Y$ es que es necesario saber gestionar las emociones y ser capaz de controlarlas por uno mismo, ya que la falta de autocontrol puede ser la causante de comportamientos disruptivos y de bajo rendimiento académico.

Las emociones son las que activan nuestra motivación moviéndonos a actuar en la búsqueda del placer. La motivación es interna pero existen factores externos que pueden favorecer dicha motivación, por ejemplo el interés y motivación del propio docente o trasladar al alumnado a aquello que va aprender, va a tener utilidad fuera del aula.

En definitiva, el motor que enciende nuestra motivación es la emoción, siendo desde aquí donde se activa nuestra atención favoreciendo así el aprendizaje.

Entre los objetivos, la neurodidáctica pone de relieve la necesidad de desarrollar personas con un pensamiento crítico y creativo pues sólo así podremos avanzar, cambiar lo que ya conocemos, adaptarnos a los cambios... caminar a lo desconocido aunque nos haga sentir inseguros y perdidos.

Podríamos remontarnos a Vygotski e incluso a Platón, como bien recuerda H. Read (1986), para hablar de la importancia del desarrollo de la creatividad. Pero hay otros autores actuales que valoran y promueven un 
aprendizaje basado en la creatividad, es el caso de Ken Robinson (2006), quien considera y afirma que los niños nacen artistas pero durante su evolución a la etapa adulta, la sociedad y el sistema educativo, va coartando poco a poco su creatividad y no la entiende como una capacidad aislada, sino ligada a otros factores como el juego, al que hacíamos referencia en el apartado anterior, por ser una herramienta que favorece la participación, el aprendizaje y la autoestima. Y es que el juego nos permite perder el temor a equivocarnos, a cometer un errores.

Teoría que Rafael Lamata (2005) comparte cuando nos habla de como la creatividad es un viaje a lo desconocido, donde la investigación y el juego se ponen en funcionamiento, en busca del conocimiento. Se trata de buscar respuestas diferentes a las ya conocidas, respuestas que puedan cambiar y mejorar algo. Para ello se hace necesario controlar nuestras emociones y aparcar los miedos, desligarnos de la idea de fracaso que nos puede incluso paralizar, para emprender ese viaje a la creatividad, a la búsqueda de lo nuevo, de lo diferente.

Pero para que se produzca ese proceso creativo, no sólo son necesarias las experiencias a las que Vygotski hacía alusión, Lamata añade la conciencia por su capacidad de valorar la información de una determinada experiencia que será filtrada por nuestra propia realidad.

Volviendo al valor que la sociedad confiere a la creatividad, este autor nos advierte de la gran barrera que muestra la sociedad a ésta, coartando así su desarrollo. Algo que podemos observar en diferentes ámbitos: los sistemas de comunicación donde nos muestran una realidad concreta que condiciona la nuestra, limitando dar respuestas creativas; las agrupaciones creadas en función al rango socioeconómico de cada individuo, tipo de educación, estética, etc; la percepción del valor atribuida por parte de la sociedad, es decir, el valor económico que rige nuestra sociedad y es el que marca la escala de valores cotidianos que condiciona nuestra experiencia.

Entre los ámbitos que Lamata clasifica, nos interesa especialmente aquel ligado al sistema educativo, ya que es la base de la sociedad y por supuesto de nuestra investigación.

El sistema educativo, como afirma Robinson (2010) se presenta de forma lineal, algo contradictorio a cómo lo hace la vida, la cual se muestra de forma orgánica. Debemos comenzar por conocer el valor de la imaginación y la creatividad para saber apreciarla y tratarla como un regalo que se debe cuidar. 
Generalmente se valora la creatividad como algo positivo, aunque como afirma Lamata (2005), finalmente en el trabajo tendemos a repetir pautas establecidas donde el cambio y la innovación se recibe como un problema. Debemos valorar que durante el proceso creativo surgen dificultades que nos permiten salir de la rutina, para disfrutar del proceso y del momento.

Y es que la educación absorbe de la sociedad ese doble valor de la palabra creatividad, no sólo a la hora de modificar nuestras pautas y rutinas como afirma Lamata, sino cuando observamos y analizamos la organización e importancia que algunas materias adquieren en detrimento de otras.

Pero la creatividad no es exclusiva de músicos, escritores, artistas plásticos, cineastas..., la creatividad lo invade todo y se puede explorar, como reconoce Lamata, desde diferentes ámbitos: a través de un itinerario (pautas que se establecen a partir de una tarea o idea); las personas como recurso (valorar y aprovechar la variedad de opiniones e ideas); la configuración de talleres (donde cada actividad didáctica se entiende como una obra única con un principio, desarrollo y final); las fases de los procesos de aprendizaje (que transcurren por diferentes etapas como son expectación, incomprensión y refuerzo donde debemos pasar del «no se puede-se puede» reforzando así nuestra confianza); procesos y resultados (donde se valore tanto el acierto como el error, algo que está muy ligado con el proceso creativo); novedad o repetición (cuando hacemos referencia a un aprendizaje creativo, novedad y repetición son imprescindibles); incorporar la creatividad en cualquier proceso educativo (a través de ésta se puede trabajar cualquier contenido, favoreciendo su entendimiento y aprendizaje a la vez que promueve la motivación y la investigación); principios actitudinales (donde intervienen diferentes factores como la atención-dispersión, la rapidez-darse tiempo, la certeza-incertidumbre, el trabajo-juego,...).

En definitiva, la creatividad es el diálogo que se genera entre nuestro mundo interior y el mundo exterior.

Para favorecer la actitud creativa del alumnado, el papel del docente es la de guiar a éste para que cada uno busque sus propias respuestas, aprendiendo a discriminar y observar los procesos de descubrimiento, despertando su motivación y siendo capaces de ver las soluciones durante el proceso. Es importante que el docente genere un ambiente que anime al alumnado a entrar en juego, para que éste se convierta en participante y desde aquí, aprenda a utilizar los contenidos con claridad y profundidad siendo capaz de ver el sentido o sinsentido de lo que se realiza. 
Se hace necesario un cambio en la educación, pues más que dar conocimiento se trata de generar problemas y objetivos al alumnado, para desde aquí, sea capaz de encontrar respuestas o soluciones, conectando el lado derecho e izquierdo del cerebro. Y es que, debemos saber que las dos áreas del cerebro están conectadas, no trabajan de forma aislada. Igual ocurre con el conocimiento más próximo a la realidad, la vida nos enseña de forma conjunta, los contenidos que vamos aprendiendo en nuestro entorno no vienen desglosados y separados por materias.

Y por último, la importancia del trabajo colectivo, un aprendizaje que no esté basado simplemente en la adquisición de conocimientos, es importante aprender a convivir. Se trata de conectar con los demás, buscando cada uno su espacio a la vez que se valoran las aportaciones de los demás. Buscar soluciones a los problemas de forma conjunta, abre más ventanas de actuación y por tanto de resolución. A la vez, esta convivencia puede resultar complicada pero esto provoca a su vez, maduración al tener que buscar soluciones sociales.

\subsection{Un acercamiento a metodologías interdisciplinares.}

Como nos propone Read (1986), de deben generar proyectos que integren armónicamente las áreas del currículo, pues considera que el gran defecto de la educación es el hábito de establecer territorios separados y fronteras inviolables.

Sabemos que a priori no es fácil realizar un trabajo globalizado debido a varios acontecimientos: nuestro sistema educativo se encarga de generar límites que dificultan la conexión entre las diferentes áreas; la metodología empleada, en muchos casos, sigue los mismos patrones que la recibida cuando éramos alumnos, una educación basada en la trasmisión de contenidos y alejada de la experimentación y la motivación; y por último señalar el miedo a no cumplir los objetivos marcados por el sistema educativo y por tanto, miedo a fracasar.

Pero estamos convencidos que un modelo interdisciplinar favorece y enriquece el aprendizaje del alumnado, algo que ya hemos avanzado con anterioridad.

Fernando Hernández (2000), plantea un cambio de sentido en la educación actual, basado en una nueva concepción del currículum transdiciplinar y a una construcción del pensamiento complejo, un método que fomente el análisis y la interpretación de la información obtenida, promoviendo así la comprensión y construcción de significados en dicho proceso. 
Y es que se hace necesario atender los acontecimientos señalados anteriormente para buscar respuestas más acordes. Según Hernández es imprescindible un cambio de rumbo en la educación, donde el conocimiento que se adquiere de manera memorística se adapte a las nuevas necesidades que plantea la sociedad actual, favoreciendo y valorando la actividad manual y la intuición como parte del aprendizaje y no al mero aprendizaje conceptual.

Una metodología que favorezca la actitud crítica en el alumnado, donde se relacionen los contenidos de las diferentes áreas del currículo, pues es así como se muestran en la realidad. Esta red de conceptos refuerza los conocimientos, generando que sean más funcionales y duraderos.

J. Antonio Marina (2016) en su libro Objetivo: generar talento. Cómo poner en acción la inteligencia, nos habla de cómo nuestros recuerdos se enlazan con recuerdos casi infinitos siendo esta asociación el mecanismo rector que hace posible la ampliación de esas redes. Pero esta asociación puede hacerse de manera automática o voluntaria.

Si recordamos las afirmaciones de Robinson (2010), cuando nos advierte sobre el tipo de aprendizaje que se genera en el aula, basado en una estructura lineal donde las áreas se delimitan imposibilitando la interacción entre las materias, contrario al aprendizaje natural del individuo, el cual se muestra de forma dinámico y orgánico, concluimos en la necesidad de que se produzca un cambio.

Algo que comparte María Acaso (2015), quien considera la necesidad de que el sistema educativo evolucione paralelamente a la sociedad de su tiempo, puesto que como afirma esta autora, la educación está estancada en el siglo XIX y propone, entre otros, utilizar una metodología globalizada que parta desde el arte, ya que las artes plásticas son una herramienta que favorece y facilita una metodología interdisciplinar, siendo a su vez adecuada para avanzar y atender al alumnado de nuestra época. Mientras Pedro Guerrero (2008) nos recuerda en su libro Metodología de investigación en educación literaria (el modelo ekfrástico), el valor de una metodología globalizada desde la comparación de la literatura con otras áreas, considerando a ésta, capaz de introducir al alumnado en nuevas formas de trabajo a partir de un modelo estético, interdisciplinar e intertextual. Esta metodología, según Guerrero, activa en el lector su capacidad de interpretación y sus conocimientos, necesarios para comprender el mensaje del texto en cuestión, generando a su vez una malla de asociaciones que suceden en el propio texto. Y considera la literatura o las artes plásticas dos herramientas favorecedoras de metodologías interdisciplinares ya que nos permiten incidir en las emociones, algo que influye y beneficia la atención y por tanto el aprendizaje. 


\subsubsection{La literatura}

Según mantiene Bettelheim (1986), la literatura tiene la capacidad de desarrollar la identidad de las personas y darnos las herramientas para solucionar los problemas a los que nos enfrentamos en la vida. Los cuentos de hadas muestran un abanico de emociones y una tipología de personajes, y por tanto de personalidades, que nos ayudan a canalizar las emociones y nos ofrecen soluciones ante diferentes adversidades a las que nos enfrentamos en nuestra vida.

Algo que Ventura y Durán (1980) también mantienen, destacando a su vez la estimulación de la fantasía e imaginación que se genera, abriendo al lector a posibilidades mucho más ricas que su propia realidad. Y continúa diciendo que la literatura es una herramienta capaz de despertar la imaginación, en contraposición a aquel pensamiento cientifista que pretende explicar todo desde la razón.

O la psicóloga clínica, Clarissa Pinkola Estés (2005) que se suma a la afirmación de cómo los cuentos presentan una serie de instrucciones capaces de guiarnos para superar la complejidad de la vida; y Pilar Carrasco Lluch (2009), que nos acerca al valor de curación de la literatura, en su tesis Estudio del valor terapéutico de la literatura infantil en los niños hospitalizados, y como los personajes de los cuentos pueden ser un referente en esos momentos de crisis, para superar miedos y soledad que lleva consigo la hospitalización.

Por tanto, la literatura: nos ayuda a educar y controlar nuestras emociones, algo necesario para saber enfrentarnos a los problemas desde una postura calmada; favorece el desarrollo de la imaginación y la creatividad contribuyendo no sólo al desarrollo del niño/a sino que incita una actitud crítica y resolutiva; y desarrolla el lenguaje oral y escrito.

\subsubsection{Las artes plásticas como herramienta integrante}

Hemos resaltado algunos aspectos importantes de la literatura y es ahora cuando analizamos el valor de las artes plásticas no sólo como herramienta globalizadora sino además enriquecedora. El arte fomenta la creatividad e imaginación favoreciendo el desarrollo de un pensamiento crítico y abierto, tan necesario en la búsqueda de soluciones diferentes a las convencionales.

Eisner (2004), defiende la necesidad de educar a través de las artes por ser las encargadas del refinamiento de nuestros sentidos, cumpliendo una función valiosísima para desarrollar la imaginación. 
Herbert Read (1986) partiendo de la tesis defendida por Platón donde el arte debe ser la base de la educación, junto al planteamiento del principio de libertad basado en el juego, plantea tener en cuenta: educación visual, educación plástica, educación musical, educación cinética, educación verbal y educación constructiva.

Y en la línea de los autores anteriores encontramos a Lowenfeld y Lambert (1984), quienes consideran el arte como un proceso continuo que desarrolla la capacidad creadora, puesto que cada niño trabaja desde su nivel de desarrollo para producir nuevas formas y enfrentándose a la superación de innumerables problemas. Y, por tanto, es interesante considerar la capacidad creadora como ese proceso continuo para el cual la mejor preparación es la creación misma. Y defienden la necesidad tanto de preservar como de desarrollar la capacidad innata de investigar, explorar y descubrir, que presenta la infancia.

A pesar de esto, actualmente en el sistema educativo español, la Educación Primaria el área de Educación Artística incluye la Educación Plástica y la Educación Musical. Pero mientras la Educación Plástica no cuenta con una especialidad docente, la música es impartida por maestros especialistas.

Como observamos, los factores señalados al inicio del artículo (creatividad, juego, interdisciplinariedad y emociones), van entrelazándose y adquiriendo un valor que les hace ser útiles para transferirlos al aula. Factores que están ahí y pueden ser una de las claves para que se produzca la motivación y desde aquí el aprendizaje.

\section{MÉTODOS Y MATERIALES: UN MODELO DE INTERVENCIÓN DIDÁCTICA "DEL BARROCO AL ARTE CONTEMPORÁNEO".}

Como mencionamos al inicio, este trabajo parte de la implementación del proyecto "Del barroco al arte contemporáneo" que se enmarca dentro del Programa "Talleres de Enriquecimiento Extracurricular para alumnos con altas capacidades" en la Región de Murcia.

Las necesidades que presentan este tipo de alumnado y las dificultades que se plantean dentro de un aula, para ofrecerles la atención adecuada, nos lleva a hablar del modelo llevado a cabo en la Región de Murcia, España. Dentro del artículo Talleres de enriquecimiento extracurricular para alumnos de altas habilidades, de los autores A. Rojo, C. Garrido, G. Soto, M. Sainz, M.C Fernández y D. Hernández (2009), se explica la labor realizada en la Región de Murcia para alumnado de altas habilidades (superdotados y talentos). 
Estos talleres surgen en 2006 cuando el Servicio de Atención a la Diversidad de la Consejería de Educación, Ciencia e Investigación (en la actualidad Consejería de Educación, Juventud y Deportes) de la Región de Murcia, demanda un programa que abastezca a este alumnado que ha sido identificado desde 2003 por el grupo de investigación Altas Habilidades de la Universidad de Murcia, España.

Este programa es un complemento a los objetivos curriculares y a la formación reglada, llevándose a cabo fuera del horario escolar. Entre sus objetivos se plantea el desarrollo de las capacidades del alumnado, para lo cual ofrece contextos enriquecidos que le permitan, junto con un aprendizaje autónomo, desarrollar su pensamiento divergente y sus habilidades sociales desde un contexto lúdico.

\subsection{Muestra \\ 3.1.1 Participantes}

Para atender al alumnado de altas capacidades, es importante conocer las características y preocupaciones que presentan, analizar la realidad en la que se encuentran inmersos tanto el profesorado como el alumnado, donde el ratio del aula es grande y en muchos casos el docente encuentra dificultades para presentar atención específica. Esto puede generar desmotivación y aburrimiento en el alumnado y en un futuro no lejano, abandono del sistema educativo.

Por ello, en esta investigación queremos acercarnos a estos perfiles específicos, con la intención de atenderlos desde un proyecto que fomente el trabajo experimental en un marco interdisciplinar, que incida en las emociones a la vez motive y favorezca el trabajo cooperativo.

Entre los participantes se encuentra la tutora del taller y 11 alumnos y alumnas de $6^{\circ}$ curso de Educación Primaria provenientes de diversos municipios próximos a Murcia, España. El taller cuenta con un total de 11 niños y niñas con los siguientes perfiles: 3 superdotados y 8 conglomerados (de los cuales 6 son académicos + figurativos, 1 académico + matemático + creativo y 1 académico + figurativo + matemático).

Es un grupo que participa, comparte y trabaja bien tanto a nivel individual como grupal. En general, cada alumno/a es cuidadoso y meticuloso con el trabajo realizado a la vez que muy creativos. 


\subsubsection{Materiales}

Dentro de los materiales diferenciamos entre dos clasificaciones: aquellos utilizados para el desarrollo del taller y los necesarios para la realización de la investigación.

En el primer grupo destacamos un libro que es donde se partió para el desarrollo del taller, el álbum ilustrado Concertina y el dragón (Teresa Navarro, 2012). Este libro acerca al alumnado al tema que se va a trabajar, la obra de Velázquez por ello, además se puso a disposición del mismo, libros de historia donde ampliar información sobre el estilo artístico el barroco y en concreto, sobre la obra del autor que nos concierne.

Además se puso a disposición material plástico diverso que le sirviera para desarrollar y enriquecer sus creaciones. Los materiales utilizados son de diversa índole (pintura, tejidos, papeles, hilo, aguja...), todos ellos para llevar a cabo el proyecto artístico diseñado.

Atendiendo al marco de la investigación, la información recabada parte de cuestionarios que desde el Equipo de Altas Capacidades nos facilitan. Este cuestionario está dividido en cuatro secciones:

- Primera sección: está compuesta por nueve ítems. A su vez esta sección se divide en dos subgrupos donde seis ítems las decide del propio docente con el propósito de recabar información que considera relevante (temática, metodología, técnicas empleadas...) limitándose a responder entre cuatro opciones (nada, poco, mucho, bastante); y los tres ítems restantes están enfocados a saber qué actividad ha gustado más y menos al alumnado y a partir de aquí, qué cambiaría a partir de respuestas más abiertas.

- Segunda sección denominada Valoración del grupo de compañeros: está formada por cuatro ítems, dos de desarrollo de respuestas cerradas (nada, poco, mucho, bastante) y dos de respuesta abiertas.

- Tercera sección Valoración del profesor/profesora: donde hay dos ítems que recogen con respuestas cortas si el docente se ha esforzado en generar actividades divertidas y crear grupo.

- Cuarta sección Valoración de uno mismo: subdivida en ítems con respuestas cortas (nada, poco, mucho, bastante) donde recoge información sobre la adquisición de conocimientos nuevos y si ha trabajado con ilusión; y un ítem de desarrollo donde expongan qué tipos de taller les gustaría hacer. 
La última sesión, el día de presentación del trabajo realizado a las familias, es cuando uno de los integrantes del Equipo de Altas Capacidades reparte, en formato papel, el cuestionario para ser rellenado por el alumnado. Posteriormente el Equipo facilita a los docentes los cuestionarios.

De los cuatro apartados del cuestionario, para la investigación que nos concierne, se han tenido en cuenta siete ítems extraídos de la primera y cuarta sección.

\subsubsection{Procedimiento y análisis}

Descripción y temporalización del taller:

Del barroco al arte contemporáneo (2015), es el título del proyecto realizado dentro del programa de "Talleres de Enriquecimiento Extracurricular para alumnos con altas capacidades" en la Región de Murcia, el cual tiene una duración de $21 \mathrm{~h}$ distribuidas en 7 sesiones.

La columna vertebral este taller, es el álbum ilustrado "Concertina y el dragón" (T. Navarro, 2012), que aborda la obra de Velázquez, unida a contenidos matemáticos y musicales. Esta obra motiva e introduce al alumnado, a través de la literatura, en el conocimiento del barroco y conceptos matemáticos, desde una perspectiva lúdica y emocional. Dicho libro es especialmente aconsejable para este perfil de alumnado, puesto que aborda el tema de la aceptación de las diferencias, favoreciendo una imagen positiva de sí mismo. Además, como afirma Navarro (2015), el dragón protagonista no aparece representado en la ilustración, en aras a conseguir que cada lector imagine su propio dragón.

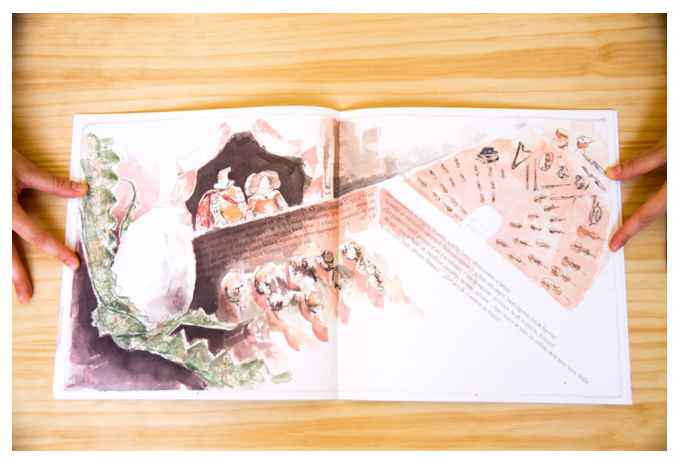

Figura 1. Imagen del álbum ilustrado Concertina y el dragón Navarro (2012). 
La metodología aplicada promueve un clima de participación entre docente y alumnado, favorece el aprendizaje cooperativo y desarrolla un aprendizaje globalizado a través de hilos conductores interconectados entre las distintas materias.

Una experiencia similar fue implementada años antes en una clase ordinaria, con la tutora Rosa Cerrahína, en $6^{\circ}$ Curso de Primaria el CEIP Virgen de las Huertas en el año 2013, con gran acogida por parte del alumnado. Ante la posibilidad de trabajar con alumnado de altas capacidades nos surge la siguiente duda: ¿La metodología interdisciplinar basada en proyectos que fomenten el trabajo artístico, participativo, experimental y manipulativo es adecuada para implementarla a estos perfiles específicos?.

Por tanto, nuestro trabajo inicial consiste en crear una actividad estimulante sobre el barroco, que promueva la motivación del alumnado y despierte el deseo de profundizar sobre el tema, atendiendo a su vez a las necesidades planteadas por el programa "Talleres de Enriquecimiento Extracurricular: una respuesta educativa al Alumnado de Altas Capacidades" (2008).

Los objetivos de dicho taller son diversos y relacionados con las diferentes disciplinas que trabaja:

- Desarrollar conexiones interdisciplinares principalmente entre tres áreas (arte, matemáticas y literatura), fomentando un aprendizaje significativo en el alumnado.

- Implicar al alumnado emocionalmente a través de la literatura y el arte, tomando como base el libro Concertina y el dragón.

- Introducir al alumnado en conceptos artísticos: características del barroco y obra de Velázquez y Salzillo.

- Iniciar al alumnado en el arte contemporáneo desde una práctica interdisciplinar y lúdica.

- Incentivar un trabajo cooperativo a través de la realización de actividades plásticas conjuntas, donde se respete y valoren las aportaciones y creaciones de todos.

Primera sesión.

- Comenzamos con el cuentacuentos y a continuación se realiza una puesta en común donde se perfilan algunos de los temas que se desprenden de las ilustraciones: Velázquez, el Barroco, el retrato, la moda, las matemáticas o la mitología. Todo ello da pie a plantear el proyecto, donde el alumnado se convierta en 
artista creando su propia obra, encaminando el trabajo hacia la materialización de una obra real, que posibilite una exposición artística que les introduzca en conceptos de arte contemporáneo. Propuesta que el alumnado acoge con entusiasmo. Ello implicará poner en juego habilidades relacionadas con imaginar, crear y finalmente elaborar, para plasmar la idea. Este proceso nos llevará a desarrollar múltiples estrategias para dar respuesta a los problemas encontrados.

- Imaginar y plasmar su propio dragón, partiendo de la información del álbum ilustrado.

- Reinterpretar el cuadro de "Las meninas" una vez visualizadas versiones de artistas como Picasso, Gaya o la realizada por Teresa Navarro en dicho álbum.

Segunda sesión.

- Visita al Museo Salzillo de Murcia, para estudiar in situ su obra permitiéndonos una visión mucho más cercana sobre el Barroco y sus características: composición, atuendos, decorado de sus telas, los colores o los volúmenes.

Ahora es el momento de poner en valor las diferencias entre la obra de Velázquez (retratos de corte y mitología principalmente) y Salzillo (obra religiosa). Si Velázquez nos ofrece una información valiosa sobre la moda de la época (indumentarias, peinados, trajes, gorgueras, puños, joyas,...), y sobre el retrato y sus características (luz, postura de $3 / 4, \ldots$ ), Salzillo nos permite indagar de forma mucho más directa sobre los decorados de las telas (estofados) y los volúmenes.

Tercera, cuarta y quinta sesión.

- Una vez recogida toda esta información pasamos a crear cada uno de los componentes necesarios para la elaboración de cada uno de los trajes: crear los sellos que nos permitirán el proceso de estampación, diseñar el estampado, diseño del traje, bocetos, corte y confección con las actuaciones que se derivan de todo ello (medidas de longitud, centímetro, metro, contorno de cintura, largo de talle, largo de falda, simetrías,...), creación de cuellos y puños (a través de la papiroflexia realizamos un estudio de simetría radial, simetría axial...) y joyería (a partir de materiales reutilizables). 


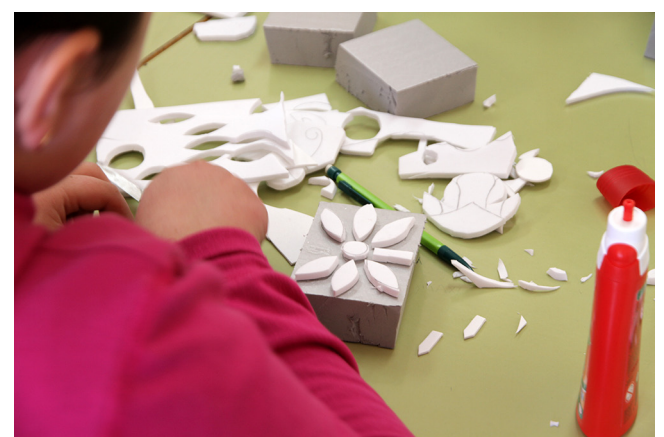

Figura 2. Imagen de alumna diseñando simetrías para estampado.

Este conglomerado de actividades está ligado a la cooperación y el aprendizaje entre iguales, pero a su vez a la utilización de conceptos históricos, artísticos, matemáticos, ...; y vinculado tanto a la creación como a la actividad manual, aunando procesos cognitivos, creativos, artesanales y manipulativos.
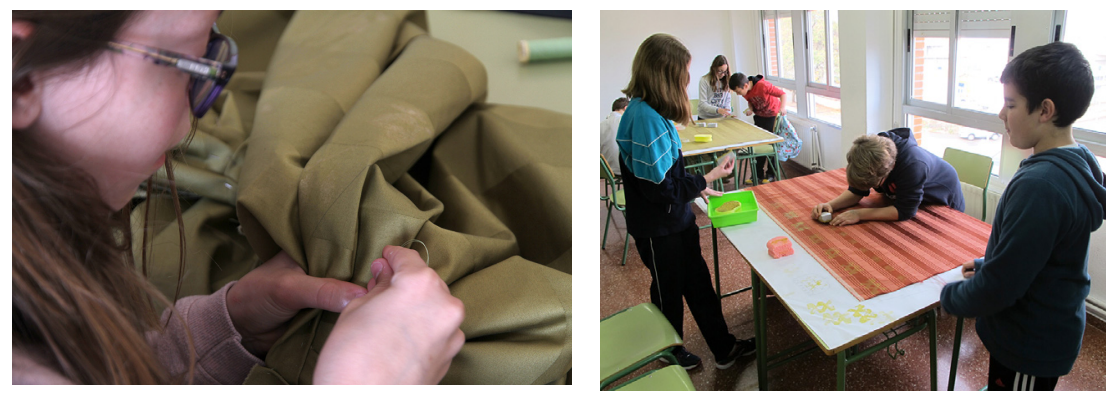

Figura 3 y 4. Imágenes del alumnado cosiendo y estampando.

\section{Sexta sesión}

- Esta penúltima sesión está dedicada al retrato, a crear nuestros propios retratos basados en artistas barrocos y artistas contemporáneos (Suzanne Jongmans, artista contemporánea que realiza retratos fotográficos reinterpretando el barroco). Para la creación de esta obra, se tuvieron en cuenta: la luz, la posición, indumentaria,... 


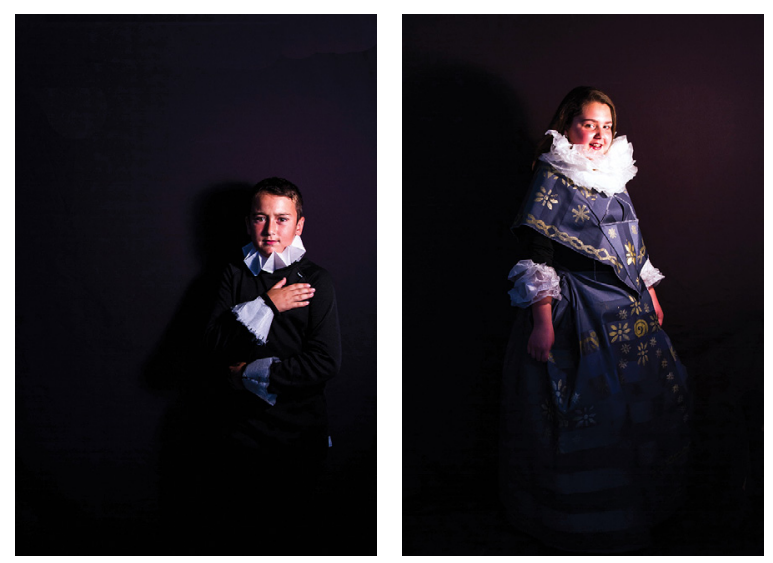

Figura 5 y 6 . Retratos del alumnado.

Séptima sesión.

- La exposición comisariada por Verónica N, se realiza en el PabeIlón 1 del Cuartel de Artillería de Murcia, y permanece abierta al público durante 15 días.

Esta última sesión se dedica al diseño y montaje de exposición. Para ello se crean varios grupos donde cada uno se encarga de una parte del montaje: estudio del espacio, colocación de las piezas e iluminación. Este proceso requiere de la solución de problemas que van surgiendo durante el montaje y por tanto, de la coordinación de los integrantes de cada grupo.

Para la inauguración se cuenta con la presencia de las familias y con parte del equipo del programa "Talleres de Enriquecimiento Extracurricular para alumnos con altas capacidades" en la Región de Murcia. En este momento el alumnado, previa preparación, hace las funciones de mediador mostrando su trabajo, los contenidos de la muestra y el proceso llevado a cabo durante el taller a los visitantes. 


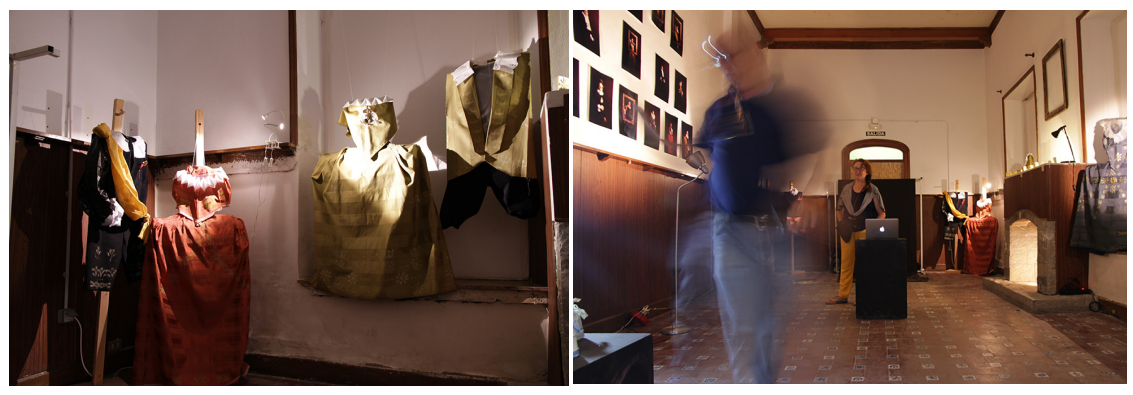

Figura 7 y 8. Imágenes de la exposición.

Es importante reseñar que no todo aconteció como estaba previsto, puesto que durante el proceso se realizaron diversos cambios:

- Se propuso que el alumnado realizara una reinterpretación de Las meninas, pero se eliminó para introducir la actividad de mediación por parte del alumnado el día de la exposición.

- Surge la idea de hacer de mediadores y guías de la exposición, algo no previsto, y que tiene gran acogida. Esto requiere un trabajo adicional pero interesante desde el punto de vista, no solo de mostrar su trabajo, sino de interiorizar el mismo para poder exponer los conocimientos adquiridos. Y, a su vez, revisar el modo de dirigirse al público, hablar con coherencia, tonos adecuados,...

\section{RESULTADOS}

Es importante conocer la valoración realizada por el alumnado a este proyecto, para comprender la necesidad de desarrollar metodologías interdisciplinares que se adecuen a los modos de aprendizaje naturales, fomentando un aprendizaje basado en la experimentación y el juego.

Pasamos a valorar y analizar los resultados de los cuestionarios obtenidos tras la realización del taller:

- A la pregunta, "Me ha gustado el tema: Del barroco al arte contemporáneo" el 54,54\% afirma que le ha gustado mucho, el $36,36 \%$ expone que bastante, $9,09 \%$ poco y $0 \%$ nada.

- En relación a la cuestión, "Me ha gustado utilizar diversas técnicas" el $81,81 \%$ afirma que le ha gustado mucho, el $18,18 \%$ expone que bastante, $0 \%$ poco y $0 \%$ nada. 
- A la pregunta "Me ha gustado trabajar en grupo" el $72.72 \%$ del alumnado responde que le ha gustado mucho, frente al $27,27 \%$ afirma que bastante, $0 \%$ poco y $0 \%$ nada.

- Ante la pregunta "Me ha gustado realizar actividades creativas" el $72.72 \%$ del alumnado responde que le ha gustado mucho, frente al $27,27 \%$ afirma que bastante, $0 \%$ poco y $0 \%$ nada.

- En la cuestión "Me ha gustado conocer la historia del barroco" el $36,36 \%$ del alumnado afirma que le ha gustado mucho, $45,45 \%$ afirma que bastante, $18,18 \%$ poco y $0 \%$ nada.

- A la pregunta " ¿Has trabajado con ilusión en las actividades del taller?" el $72.72 \%$ del alumnado responde con la valoración más alta, al $27,27 \%$ afirma que bastante, $0 \%$ poco y $0 \%$ nada.

- En la cuestión “¿Has aprendido cosas nuevas?" el 72,72\% del alumnado afirma que si, 27,27\% afirma que bastante, $0 \%$ poco y $0 \%$ nada.

\section{DISCUSIÓN}

A la vista de los resultados obtenidos, podemos concluir que el proyecto ha tenido buena acogida por el alumnado ya que valora positivamente los diferentes epígrafes del cuestionario.

Aspectos relacionados con el desarrollo de sus creaciones como, la utilización de diferentes técnicas utilizándolas para el desarrollo y creación de actividades creativas, han tenido una valoración muy alta. Y es que, es importante disponer de diversos y suficientes materiales y técnicas que sean útiles para el desarrollo del trabajo. Las actividades creativas desarrolladas, al llevar implícitas contenidos de diferentes áreas para su desarrollo, además de motivarles, se acercan a ellas desde aquella área que sienta más motivación.

En la cuestión "Me ha gustado conocer la historia del barroco", observamos que posiblemente debido a haber planteado como una actividad más teórica, a modo de clase magistral, ha tenido una valoración más negativa con respecto a actividades más dinámicas y participativas. Desde la neurodidáctica nos advierten del tiempo de atención que una persona es capaz de mantener, según determinadas características, por ello se hace necesario generar actividades más dinámicas y participativas para que el alumnado responda positivamente al proceso de aprendizaje incluso en actividades más teóricas. 


\section{CONCLUSIONES}

Encontrar la motivación desde la emoción, jugar para perder el miedo al fracaso mientras se disfruta, llegar al conocimiento poniendo en acción diferentes áreas que faciliten acceder a éste desde aquella que nos sea más favorable, son algunas de las premisas que esta investigación pone encima de la mesa, considerando necesario que formen parte integrante de nuestra metodología.

"Del barroco al arte contemporáneo" (2015) ha acercado al alumnado a estos dos estilos artísticos: incidiendo en las emociones a través del arte y la literatura; mediante una metodología interdisciplinar implicando diferentes áreas (artes plásticas, diseño de moda, literatura, matemáticas); favoreciendo la participación individual y grupal, a través del juego, y todo ello con el propósito, a su vez, de crear una obra que se exhibiera en una sala de exposiciones, acercando el trabajo del aula a la realidad.

En este proceso podemos observar diferentes ambientes: espacios de reflexión, donde se desarrolla un trabajo grupal donde experimentar y tomar decisiones; espacios ricos de aprendizaje, donde se promueven experiencias que favorecen el desarrollo de la creatividad y la expresión de sus emociones, teniendo una gran acogida y aceptación por parte del alumnado; espacio dedicado a la teoría donde se expone la historia del barroco centrado en la obra de Velázquez; y por último dos escenarios fuera del centro educativo, el primero el museo Salzillo, donde el alumnado fue nutriéndose del arte barroco del que dispone la ciudad de Murcia, y el segundo la sala de exposiciones Cuartel de Artillería de ésta misma ciudad, donde exponen su obra enriqueciendo el imaginario del alumnado y el de la sociedad sobre la que actúa.

Como se desprende del cuestionario, podemos observar un alto nivel de satisfacción. Entre los ítems más valorados que oscilan entre el 72,72\% al $81,81 \%$, encontramos: gusto por trabajar diferentes técnicas, el trabajo grupal, la realización de actividades creativas y el gusto por el aprendizaje de cosas nuevas, las cuales conectan tanto con los objetivos marcados por el Equipo de Altas Capacidades como los planteados en el propio proyecto. Algunos de estos aspectos, como el trabajo colectivo o el desarrollo de la creatividad, como se ha mencionado al inicio de esta investigación, la neurodidáctica los valora pues los considera relevantes para el desarrollo del individuo.

Los resultados de los ítems mencionados son más favorables que los resultados obtenidos en relación a la adquisición de conocimientos teóricos del barroco, algo que hemos ido analizando a lo largo de este artículo. Recordemos las últimas aportaciones de neurociencia sobre la atención en las 
clases magistrales, y como se demuestra en el cuestionario, aquellas clases donde se ofrece información teórica sin apenas reflexión y participación, son menos valoradas por el alumnado por falta de motivación e interés. Algo que concuerda con las afirmaciones de Mora (2017) cuando nos advertía que las emociones generan reacciones inconscientes que inciden no sólo en nuestro cuerpo, sino en nuestro sistema de aprendizaje; o Vygotski (1989), cuando nos hablaba del gran valor de ofrecer al niño diversas experiencias que favorezcan nuevas creaciones, resaltando a su vez el gran papel que juegan las emociones en todo este proceso, transformando los elementos que provienen de la realidad en un producto de nuestra imaginación; y Lamata cuando afirmaba la necesidad de generar procesos creativos donde aprendamos a discriminar y observar los procesos de descubrimiento que nos lleve a buscar respuestas propias y encontrar soluciones durante el proceso.

En cuanto a la parte positiva y el nivel de aceptación encontrada con respecto al proyecto interdisciplinar realizado, nos remite en parte a $\mathrm{H}$. Read y su teoría sobre el defecto de nuestro sistema educativo al generar establecimientos separados entre las áreas, abogando por proyectos interdisciplinares.

Incluso podemos afirmar, que actividades que a priori nos pueden parecer alejadas de sus principales necesidades u objetivos, no lo son, ya que en ocasiones se establecen correspondencias entre estos trabajos y su posible perfil laboral futuro. Encontramos el caso de un alumno que le gustaría ser cirujano y encontró especialmente atractivo aprender a coser, quizá debido a la repercusión que puede tener en su actividad futura.

Ante la pregunta ¿La metodología interdisciplinar basada en proyectos que fomenten el trabajo artístico, participativo, experimental y manipulativo es adecuada para implementarla a estos perfiles específicos?, podemos afirmar que sí, que dicha metodología interdisciplinar es adecuada para este perfil de alumnos.

Por tanto, de motivación y desmotivación ligado no sólo a los intereses del alumnado, sino a la metodología empleada. 


\section{BIBLIOGRAFÍA}

Acaso, M. (2015). rEDUvolution. Hacer la revolución en la educación. Barcelona, España: Ediciones Paidós Ibérica.

Bettelheim, B. (1986). Psicoanálisis de los cuentos de hadas. Barcelona, España: Editorial Crítica.

Carrasco, P. (2009). Estudio del valor terapéutico de la literatura infantil en niños hospitalizados (tesis doctoral). Universidad de Murcia, España.

Eisner, W.E. (2004). El arte y la creación de la mente. El papel de las artes visuales en la transformación de la conciencia. Barcelona, España: Ediciones Paidós Ibérica.

Equipo de Orientación Educativa y Psicopedagógica Específico de Altas Capacidades (2008). Talleres de Enriquecimiento Extracurricular: una respuesta educativa al Alumnado de Altas Capacidades. Murcia: Consejería de Educación, Formación y Empleo. Recuperado de: http://diversidad.murciaeduca.es/altascapacidades/docs/talleres enriquecimiento2008.pdf.

Guerrero, P. (2008). Metodología en investigación en educación literaria (el modelo ekfrástico). Murcia, España: Diego Marín Editor.

Guillén, J.C (2017). Una escuela con cerebro y corazón. Vigo: I Foro de Educación. Recuperado de: https://www.youtube.com/watch?v=dTTV7ZYvBjk.

Hernández, F. (2000). Los proyectos de trabajo: la necesidad de nuevas competencias para nuevas formas de racionalidad. Barcelona: Educar: revista del Departament de Pedagogia Aplicada. Recuperado de: http://www.raco.cat/index.php/educar/article/ viewFile/20726/20566.

Huizinga, J. (2010) Homo ludens. Madrid, España: Alianza Editorial.

Lamata, R. (2005) La actitud creativa. Ejercicios para trabajar en grupo la creatividad. Madrid. Editorial: narcea

Lowenfeld V. \& Lambert W. (1984). Desarrollo de la capacidad creadora. Colombia: Editorial Kapelusz.

Marina. J. A. (2016)Objetivo: generar talento. Cómo poner en acción la inteligencia.

Mora, F (2017). Neuroeducación. Solo se puede aprender aquello que se ama. Madrid, España: Alianza Editorial.

Navarro, T. (2012). Concertina y el dragón. Murcia, España: Editorial Puntodepapel.

Navarro, T. (2015). El museo del cuento: un modelo interdisciplinar e intertextual del espacio creativo entre el arte y la literatura. (Tesis doctoral). Universidad de Murcia, España. Recuperado de: https://digitum.um.es/xmlui/bitstream/10201/46774/1/EL\%20 MUSEO\%20DEL\%20CUENTO TERESA\%20NAVARRO.pdf

Navarro, V. (2015). Del barroco al arte contemporáneo [Taller]. Murcia. Recuperado de http:// www.puntodepapel.es/altas-capacidades-2015/

Pinkola, C. (2005). Mujeres que corren con los lobos. Barcelona, España: Ediciones B.

Read, H. (1986). Educación por el arte. Barcelona, España: Ediciones Paidós Ibérica. 
Robinson, K. (2006). ¿Las escuelas matan la creatividad? En Conferencia Oficial de TED, Conferencia llevada a cabo en Monterey, California. Recuperado de: http://www.ted. com/talks/ken robinson says schools kill creativity\#t-16372

Robinson, K. (2010). La revolución del aprendizaje. En Conferencia Oficial de TED, Conferencia llevada a cabo en Longbeach, California en 2010. Recuperado de: http://www.ted. com/talks/sir_ken_robinson_bring_on_the_revolution\#t-13498

Romo, A., Garrido, C., Soto, G., Sáinz, M., Fernández, M. C. \& Hernández D. (2009). Talleres de enriquecimiento extracurricular para alumnos de altas habilidades. Revista Electrónica Interuniversitaria de Formación del Profesorado, 13(1).

Ventura, N. \& Durán, T. (1980). Cuentacuentos, una colección de cuentos... para poder contar. Madrid: España, Editorial Pablo del Río.

Vigostsky, L.S. (1989). El desarrollo de los procesos psicológicos superiores. Barcerlona: España, Editorial Crítica. 